\title{
Estudo da Divergência Genética entre Quatro Linhagens de Matrizes de Frangos de Corte Utilizando Técnicas de Análise Multivariada ${ }^{1}$
}

\author{
Cristina Fontes Araújo Viana ${ }^{2}$, Martinho de Almeida e Silva ${ }^{3,4}$, Aldrin Vieira Pires ${ }^{5}$, \\ Paulo Sávio Lopes ${ }^{4,6}$, Marcelo Piassi ${ }^{7}$
}

\begin{abstract}
RESUMO - O desempenho de duas linhagens de matrizes de frangos de corte, desenvolvidas pela Universidade Federal de Viçosa - UFV ( $\mathrm{M}_{1}$ e $\left.\mathrm{F}_{1}\right)$, foi testado em relação a duas marcas comerciais $\left(\mathrm{C}_{1}\right.$ e $\left.\mathrm{C}_{2}\right)$, usando métodos de análise multivariada para a avaliação da divergência genética. Foram avaliadas quatro características de importância econômica: idade à maturidade sexual (IMS), número de ovos (NO), peso médio do ovo (PO) e peso das matrizes (PM), em três períodos da vida produtiva das aves, inicial (25aa à $32^{\mathrm{a}}$ semana de idade), médio ( $48^{\mathrm{a}}$ a $56^{\mathrm{a}}$ semana de idade) e total (25⿳a à $62^{\mathrm{a}}$ semana de idade). O estudo da divergência genética entre as linhagens foi feito por meio da análise de variância multivariada, da análise de agrupamento, usando a distância generalizada de Mahalanobis e o método de otimização de Tocher, e da análise por meio de variáveis canônicas. A análise de agrupamento nos períodos inicial e médio agrupou os quatro genótipos em dois grupos, sendo o primeiro formado pelas marcas comerciais e o segundo, pelos genótipos da UFV. No período total, houve formação de dois grupos, o primeiro formado pelos genótipos $\mathrm{C}_{1}, \mathrm{~F}_{1}$ e $\mathrm{M}_{1}$ e o segundo, por $\mathrm{C}_{2}$. Na análise por meio de variáveis canônicas, verificou-se que as duas primeiras variáveis canônicas foram suficientes para explicar mais de $92 \%$ da variação total nos três períodos. As características que mais contribuíram para a divergência foram peso médio do ovo e peso das matrizes.
\end{abstract}

Palavras-chave: análise de agrupamento, divergência genética, frango de corte, variável canônica

\section{Study of Genetic Divergence Among Four Broilers Breeder Lines Using Multivariate Analysis}

\begin{abstract}
The performance of two broiler breeder lines, developed by Federal University of Viçosa - UFV (M1 and F1) was tested against two mainly trade mark lines $(\mathrm{C} 1$ and $\mathrm{C} 2$ ), using methods of multivariate analysis for the evaluation of the genetic divergence. Four important economic traits were evaluated: age at sexual maturity (IMS), egg number (NO), average egg weight (PO) and body weight (PM), during three periods of the productive life of the birds: initial ( $25^{\text {th }}$ to $32^{\text {nd }}$ week of age), medium ( $48^{\text {th }}$ to $56^{\text {th }}$ week of age $)$ and total ( $25^{\text {th }}$ to $62^{\text {nd }}$ week of age). The study of the genetic divergence among the lines was made by means of multivariate variance analysis, cluster analysis using the generalized distance of Mahalanobis and the method of optimization of Tocher, and the analysis by canonical variables. The cluster analysis of the traits in the initial and medium periods grouped the four genotypes in two groups, the first was formed by the trademark lines and the second by the genotypes of UFV. In the total period, two groups were formed, the first one by the $\mathrm{C} 1, \mathrm{~F} 1$ and $\mathrm{M} 1$ genetic groups and the second by $\mathrm{C} 2$. In the analysis by canonical variables, it was observed that the first two canonical variables accounted for more than $92 \%$ of the total variation in the three periods. The traits that contributed the most to the genetic divergence were average egg weight and body weight.
\end{abstract}

Key Words: broiler, canonical variable, cluster analysis, genetic divergence

\section{Introdução}

Estudos de divergência genética podem ser utilizados para avaliar o comportamento de genótipos em diferentes ambientes, avaliar a superioridade de alguns genótipos sobre outros, identificar genótipos divergentes que possam ser utilizados como progenitores em programas de hibridação e relacionar a divergência genética com a heterose (PIASSI, 1994).

$\mathrm{Na}$ área de melhoramento genético, estudos de diversidade genética entre grupos de progenitores têm como objetivo básico identificar as combinações híbridas com maior heterozigose, de maneira que haja maior possibilidade de recuperação de genótipos superiores nas gerações segregantes. A avaliação desta diversidade genética é feita pelos estudos de divergência

\footnotetext{
1 Parte da Tese do primeiro autor para a obtenção do título de Mestre em Genética e Melhoramento - UFV (Financiamento: FINEP, CNPq, FAPEMIG).

2 MS em Genética e Melhoramento/UFV.

3 Professor da Universidade Federal de Minas Gerais.

4 Pesquisador do CNPq.

5 Estudante de Doutorado em Zootecnia - UFV, Viçosa, MG. E.mail: avpires@alunos.ufv.br

6 Professor do Departamento de Zootecnia - UFV, Viçosa, MG. E.mail: plopes@mail.ufv.br

7 Geneticista Perdigão Agroindustrial/SA, Arceburgo, MG.
} 
genética (CRUZ e REGAZZI, 1997).

Para predizer a divergência genética, várias técnicas de análise multivariada podem ser aplicadas, entre as quais são citadas a análise por meio de componentes principais, a análise por meio de variáveis canônicas e a análise de agrupamento.

Para muitos tipos de dados biológicos, há correlação entre variáveis, sendo que informações providas por análises univariadas isoladas podem ser incompletas. Assim, técnicas de análise multivariada combinam, simultaneamente, múltiplas informações provenientes de uma unidade experimental, que não são possíveis de serem obtidas com o uso da análise univariada.

Estudos de divergência genética são geralmente realizados utilizando a distância generalizada de Mahalanobis $\mathrm{D}^{2}$ e o método de otimização de Tocher (RAO, 1952), como técnica de agrupamento. Neste método, é estabelecido o critério de manter a distância média intragrupo sempre inferior a qualquer distância intergrupo (CRUZ e REGAZZI, 1997).

Outra técnica utilizada nos estudos de divergência genética é a análise por meio de variáveis canônicas, que consiste na transformação das variáveis originais em variáveis padronizadas e não-correlacionadas, com a característica de manter o princípio do processo de conglomeração com base na distância $\mathrm{D}^{2}$ de Mahalanobis (Mahalanobis, 1936, citado por CRUZ, 1990), além de considerar as matrizes de covariâncias residuais e fenotípicas das características avaliadas. O novo conjunto de varáveis, em ordem de estimação, retém o máximo de informação em termos de variação total. Estas variáveis explicarão tanto melhor a variabilidade manifestada entre os indivíduos avaliados quanto menor for o número de variáveis que acumulem pelo menos $70 \%$ da variação total (CRUZ, 1990).

Ao determinar o número de variáveis canônicas que acumulam um mínimo de $80 \%$ da variância total disponível, estimam-se os escores de cada variável canônica que podem ser plotados em gráficos bi ou tridimensionais, sendo as variáveis canônicas usadas como eixos de referência, em que podem ser visualizadas as distâncias gráficas que representam as similaridades e dissimilaridades entre genótipos (PIASSI, 1994).

Em melhoramento animal, trabalhos envolvendo análises multivariadas ainda são bem escassos no Brasil, principalmente na área de avicultura (ARAÚJO, 1995), muitas vezes, por falta de domínio das técnicas multivariadas ou, talvez, ainda por fugir às análises que são tradicionalmente realizadas.
Os objetivos do presente trabalho foram avaliar o comportamento de duas linhagens de matrizes de frangos de corte da UFV em relação a duas marcas comerciais e estudar a divergência genética entre estas linhagens utilizando técnicas de análise multivariada.

\section{Material e Métodos}

Este trabalho foi conduzido no Departamento de Zootecnia (DZO) do Centro de Ciências Agrárias da Universidade Federal de Viçosa (UFV), Viçosa, MG, no período de outubro de 1991 a janeiro de 1993.

Foram utilizadas quatro linhagens de matrizes pesadas, duas desenvolvidas na UFV (M1 e F1) e duas provenientes de marcas comerciais $(\mathrm{C} 1$ e $\mathrm{C} 2$ ) existentes no mercado. Os pintinhos foram criados do $1 \underline{0}$ ao $15 \underline{\text { o }}$ dia de idade seguindo o manejo adotado na Granja de Melhoramento de Aves/DZO/UFV. Após 15 dias de idade, as matrizes foram alojadas em um galpão e distribuídas, aleatoriamente, em 240 boxes $(1,15 \times 1,50 \mathrm{~m})$. Foi utilizada a proporção de 60 machos e 300 fêmeas por linhagem, sendo alojados um macho e cinco fêmeas por boxe.

As características avaliadas foram: idade à maturidade sexual (IMS), número de ovos (NO), peso médio do ovo (PO) e peso das matrizes (PM), em três períodos da vida produtiva das aves: inicial (25aa $32^{\text {a }}$ semana de idade), médio (48 $8^{\mathrm{a}}$ à $56^{\underline{a}}$ semana de idade) e total (25a à $62^{\underline{a}}$ semana de idade).

O modelo estatístico foi definido considerando o delineamento inteiramente casualizado com $k$ tratamentos e $j$ repetições, em que são medidas $p$ características:

$$
\mathrm{Y}_{\mathrm{ijr}}=\mu_{\mathrm{r}}+\mathrm{G}_{\mathrm{ir}}+\mathrm{e}_{\mathrm{ijr}}
$$

em que

$$
\begin{aligned}
& \quad \sum_{i=1}^{k} G_{i r}=0, \forall r, \mathrm{i}=1,2, \ldots, \mathrm{k} ; \mathrm{j}=1,2, \ldots, \mathrm{J} ; \\
& \mathrm{r}=1,2, \ldots, \mathrm{p} \\
& \mathrm{Y}_{i j r}=\text { valor observado da característica } r, \mathrm{na} \\
& \text { repetição } j \text { do genótipo } i ; \\
& \mu_{r}=\text { média geral da característica } r ; \\
& \mathrm{G}_{i r}=\text { efeito do genótipo } i \text { na característica } r ; \mathrm{e} \\
& \mathrm{e}_{i j r}=\text { erro aleatório atribuído à observação } \mathrm{Y}_{i j r},
\end{aligned}
$$
em que os e'ij $=\left(\mathrm{e}_{i j 1}, \ldots, \mathrm{e}_{i j p}\right)$ têm distribuição multinormal p-dimensional com vetor nulo de médias e matriz de variâncias e covariâncias $\sum$ comum a todas as combinações $i$ e $j$.

Na análise de variância multivariada, obtêm-se as matrizes $T, H$, e $E$, que são matrizes quadradas de ordem $p$ (características) de somas de quadrados 
1076 Rev. bras. zootec.

e produtos, sendo $T$ referente à soma de quadrados e produtos totais; $H$, à de tratamentos (genótipos); e $E$, à de resíduo. O teste de Roy foi utilizado, segundo DEMETRIO (1985), para testar a hipótese de nulidade dos vetores $\left(\mathrm{G}_{\mathrm{i}}\right)$ de efeitos de tratamentos (genótipos).

Nas análises de agrupamentos, adotou-se a distância generalizada $\mathrm{D}^{2}$ de Mahalanobis, sobre a qual se empregou o método de otimização de Tocher como método de agrupamento para a formação dos grupos genéticos similares (CRUZ e REGAZZI, 1997). A distância generalizada $D^{2}$ de Mahalanobis foi a medida utilizada para estabelecer o grau de divergência genética nos quatro genótipos estudados. Esta distância $\mathrm{D}^{2}$ entre dois genótipos é calculada de acordo com a fórmula definida por Mahalanobis, em 1936, e apresentada por RAO (1952).

Os métodos aglomerativos diferem dos demais, por dependerem de medidas de dissimilaridade estimadas previamente, como a distância Euclidiana ou a distância generalizada de Mahalanobis, entre outras. Já no método de componentes principais e, também, no da análise canônica, o objetivo é avaliar a similaridade dos progenitores por intermédio de uma dispersão gráfica, em que se consideram, em geral, dois eixos cartesianos (CRUZ e REGAZZI, 1997).

A distância generalizada $\mathrm{D}^{2}$ foi obtida por meio de variáveis transformadas, em que se combinam as variáveis originais, cujas variâncias e covariâncias residuais são iguais a 1 e 0 , respectivamente. Para a obtenção deste conjunto de variáveis nãocorrelacionadas $\mathrm{Z}_{\mathrm{r}}(\mathrm{r}=1,2, \ldots, \mathrm{p})$, a partir do conjunto de variáveis originais $X_{r}$, utilizou-se a técnica de inversão por condensação pivotal, da matriz de dispersão residual $\Sigma$. Com essa técnica de condensação pivotal a matriz de dispersão residual é reduzida a uma matriz identidade $I$, em que se obtém a distância $D_{i i^{\prime}}^{2}$, por meio da expressão

$$
D_{i i^{\prime}}^{2}=\sum_{r=1}^{p}\left(Z_{i r}-Z_{i^{\prime} r}\right)^{2}
$$

em que

$\mathrm{Z}_{\text {ir }}=$ média da r-ésima variável transformada pelo processo de condensação pivotal.

Adotou-se como matriz de dissimilaridade a de distância generalizada de Mahalanobis, na qual é inicialmente identificado o par de cruzamentos $i i^{\prime}$, que apresenta o menor valor de distância, formando assim o primeiro grupo. Em seguida, avalia-se a possibilidade de incluir mais um genótipo no grupo ou avalia-se a necessidade de formação de outros grupos, obedecendo ao mesmo critério anteriormente citado.

A distância média intragrupo é dada por

$$
\sum_{i, i^{\prime}=1}^{k} \frac{D_{i i^{\prime}}^{2}}{C_{n}^{2}}
$$

em que

$$
\sum_{i, i^{\prime}=1}^{k} D_{i i^{\prime}}^{2}=\text { soma de todas as possíveis combina- }
$$

ções dos $n$ genótipos incluídos no grupo; e

$C_{n}^{2}=$ número máximo de combinações dois a dois dos n genótipos incluídos no grupo.

As distâncias médias intergrupos são calculadas somando-se as distâncias de todos os possíveis pares de genótipos entre dois grupos; esse valor é então dividido pelo número de pares formados.

Para avaliar o grau de similaridade genética entre as linhagens, foi utilizada a análise por meio de variáveis canônicas, que possibilita a identificação de grupos similares em gráficos de dispersão bi ou tridimensionais de fácil interpretação geométrica.

A solução do sistema $\left(T-\lambda_{r} \hat{\Sigma}\right) \underset{\sim r}{\alpha}=\phi$ estima as variâncias de cada variável canônica e os coeficientes de ponderação das características.

A solução de $\left|T-\lambda_{r} \hat{\Sigma}\right|=0$ estima a variância $r$, pela raiz característica (autovalor) de ordem correspondente, em que

$\mathrm{T}=$ a matriz de covariâncias entre médias de genótipos (matriz de covariâncias fenotípicas);

$\hat{\Sigma}=$ a matriz de covariâncias residuais estimada;

$\lambda_{r}=$ raízes características (autovalores); e

$\underset{\sim r}{\alpha}=$ vetor característico (autovetor) associado a cada estimativa das raízes características, e os elementos deste vetor são os coeficientes de ponderação.

A importância relativa das variáveis canônicas foi medida pela porcentagem de seus autovalores (variâncias) em relação ao total dos autovalores.

As análises foram feitas utilizando-se o software GENES (CRUZ, 1991). 


\section{Resultados e Discussão}

Verificaram-se diferenças significativas $(\mathrm{P} \leq 0,05)$ entre os vetores de médias das linhagens avaliadas nos períodos inicial e médio, mas não foi observada diferença significativa para o período total.

Observando-se as matrizes de medidas de dissimilaridade (Tabela 1), pode-se verificar que, em geral, ocorreu maior distanciamento entre os genótipos no período inicial em relação aos períodos médio e total. Isto pode ser explicado pelo fato de que, no período inicial, as aves estavam no início de produção, variando o número e o peso médio dos ovos, bem como o peso corporal das matrizes. No período médio, o distanciamento foi menor e, no período total, diminuiu ainda mais, pois as aves já estavam mais estáveis que no período inicial, o que permitiu maior aproximação das médias das quatro linhagens.

O padrão de agrupamento das quatro linhagens de matrizes pesadas, nos três períodos estudados, pode ser observado na Tabela 2. A contribuição relativa dos caracteres para a divergência, segundo SINGH (1981), encontra-se na Tabela 3.

Tabela 1 - Distância generalizada de Mahalanobis $\left(D^{2}\right)$ entre pares de linhagens nos períodos ${ }^{1}$ inicial, médio e total

Table 1 - Generalized Mahalanobis distance $\left(D^{2}\right)$ among pairs of lines in the initial, medium and total periods ${ }^{1}$

\begin{tabular}{lrccc}
\hline Linhagem & \multicolumn{4}{c}{ Período inicial(Initial period) } \\
\cline { 2 - 5 } Line & $\mathrm{C}_{1}$ & $\mathrm{C}_{2}$ & $\mathrm{M}_{1}$ & $\mathrm{~F}_{1}$ \\
\hline $\mathrm{C}_{1}$ & 0 & 0,22 & 12,64 & 6,10 \\
$\mathrm{C}_{2}$ & 0,22 & 0 & 12,61 & 6,76 \\
$\mathrm{M}_{1}$ & 12,64 & 12,61 & 0 & 2,20 \\
$\mathrm{~F}_{1}$ & 6,10 & 6,76 & 2,20 & 0
\end{tabular}

\begin{tabular}{lllll}
\hline Linhagem & \multicolumn{4}{c}{ Período médio (Medium period) } \\
\cline { 2 - 5 } Line & $\mathrm{C}_{1}$ & $\mathrm{C}_{2}$ & $\mathrm{M}_{1}$ & $\mathrm{~F}_{1}$ \\
\hline $\mathrm{C}_{1}$ & 0 & 0,85 & 6,60 & 3,67 \\
$\mathrm{C}_{2}$ & 0,85 & 0 & 9,79 & 4,60 \\
$\mathrm{M}_{1}$ & 6,60 & 9,79 & 0 & 2,22 \\
$\mathrm{~F}_{1}$ & 3,67 & 4,60 & 2,22 & 0 \\
\hline Linhagem & \multicolumn{4}{c}{ Período total (Total period) } \\
\cline { 2 - 5 } Line & $\mathrm{C}_{1}$ & $\mathrm{C}_{2}$ & $\mathrm{M}_{1}$ & $\mathrm{~F}_{1}$ \\
\hline $\mathrm{C}_{1}$ & 0 & 2,18 & 2,18 & 1,54 \\
$\mathrm{C}_{2}$ & 2,18 & 0 & 6,65 & 3,63 \\
$\mathrm{M}_{1}$ & 2,18 & 6,65 & 0 & 2,05 \\
$\mathrm{~F}_{1}$ & 1,54 & 3,63 & 2,05 & 0 \\
\hline
\end{tabular}

1 Período inicial (25a à 32a semana de idade), médio (48a à 56a semana de idade) e total (25a à $62^{a}$ semana de idade).

1 Initial ( $25^{\text {th }}$ to $32^{\text {th }}$ week of age), medium ( $48^{\text {th }}$ to $56^{\text {th }}$ week of age) and total $\left(25^{\text {th }}\right.$ to $62^{\text {nd }}$ week of age) period.
No período inicial, o método de otimização de Tocher agrupou as quatro linhagens em dois grupos; o primeiro, formado pelas marcas comerciais $\left(\mathrm{C}_{1} \mathrm{e}\right.$ $\mathrm{C}_{2}$ ) e o segundo, pelas linhagens provenientes da UFV $\left(\mathrm{M}_{1}\right.$ e $\left.\mathrm{F}_{1}\right)$. Nesse período, a característica que mais contribuiu para a divergência entre as quatro

Tabela 2 - Análise de agrupamento das quatro linhagens de matrizes pesadas nos três períodos avaliados

Table 2 - Cluster analysis of four broiler breeder lines in the three evaluated periods

\begin{tabular}{lcl}
\hline $\begin{array}{l}\text { Período } \\
\text { Period }^{1}\end{array}$ & $\begin{array}{c}\text { Grupo } \\
\text { Group }\end{array}$ & $\begin{array}{c}\text { Linhagem } \\
\text { Line }\end{array}$ \\
\hline Inicial & 1 & $\mathrm{C}_{1}, \mathrm{C}_{2}$ \\
Initial & 2 & $\mathrm{M}_{1}, \mathrm{~F}_{1}$ \\
\hline Médio & 1 & $\mathrm{C}_{1}, \mathrm{C}_{2}$ \\
Medium & 2 & $\mathrm{M}_{1}, \mathrm{~F}_{1}$ \\
\hline Total & 1 & $\mathrm{C}_{1}, \mathrm{M}_{1}, \mathrm{~F}_{1}$ \\
Total & 2 & $\mathrm{C}_{2}$ \\
\hline
\end{tabular}

1 Período inicial (25a à $32^{a}$ a semana de idade), médio (48a à $56^{\underline{a}}$ semana de idade) e total (25a à 62 a semana de idade).

1 Initial (25 th to $32^{\text {nd }}$ week of age), medium ( $48^{\text {th }}$ to $56^{\text {th }}$ week of age) and total $\left(25^{\text {th }}\right.$ to $62^{\text {nd }}$ week of age) period.

Tabela 3 - Contribuição relativa das características idade à maturidade sexual (IMS), número de ovos (NO), peso médio do ovo (PO) e peso das matrizes (PM) para a divergência genética

Table 3 - Relative contribution of the traits age at sexual maturity (IMS), egg number (NO), average egg weight (PO) and body weight $(P M)$ to the genetic divergence

\begin{tabular}{ccc}
\hline $\begin{array}{c}\text { Variável } \\
\text { Trait }\end{array}$ & $\begin{array}{c}\text { Valor }(\%) \\
\text { Value }\end{array}$ \\
\hline \multicolumn{3}{c}{ Período inicial } \\
IMS & & \\
NO & & 8,43 \\
PO & 1,63 \\
PM & Períodol meriod \\
& 48,23 \\
Medium period & 41,27 \\
IMS & & \\
NO & & 9,35 \\
PO & & 11,59 \\
PM & & 47,04 \\
& 32,04 \\
IMS & Período total \\
NO & Total period & 19,41 \\
PO & & 13,01 \\
PM & & 42,67 \\
\hline
\end{tabular}

1 Período inicial (25 $\underline{a}$ à $32 \underline{a}$ semana de idade), médio (48a a $56 \underline{a}$ semana de idade) e total (25a à 62 a semana de idade).

1 Initial ( $25^{\text {th }}$ to $32^{\text {nd }}$ week of age), medium ( $48^{\text {th }}$ to $56^{\text {th }}$ week of age) and total $\left(25^{\text {th }}\right.$ to $62^{\text {nd }}$ week of age) period. 
1078 Rev. bras. zootec.

linhagens foi o peso médio dos ovos $(48,23 \%)$ e a que menos contribuiu, o número de ovos $(1,63 \%)$.

Resultado semelhante foi obtido no período médio. Nesse período, a característica que mais contribuiu para a divergência entre as quatro linhagens foi o peso médio dos ovos $(47,04 \%)$ e a que menos contribuiu, a idade à maturidade sexual $(9,53 \%)$.

No período total, as quatro linhagens foram agrupadas em dois grupos; o primeiro, formado por uma marca comercial $\left(\mathrm{C}_{1}\right)$ e pelas linhagens provenientes da UFV $\left(\mathrm{M}_{1}\right.$ e $\left.\mathrm{F}_{1}\right)$, e o segundo, pela outra marca comercial $\left(\mathrm{C}_{2}\right)$. Nesse período, a característica que mais contribuiu para a divergência entre as quatro linhagens foi o peso médio dos ovos $(42,67 \%)$ e a que menos contribuiu, o número de ovos $(13,01 \%)$. Estes resultados mostram que, apesar do agrupamento das linhagens da UFV separadamente das comerciais nos períodos inicial e médio, quando se faz a análise do período total, que é o período correspondente à vida produtiva da matriz, as linhagens da UFV foram agrupadas juntamente com uma das marcas comerciais, mostrando o bom desempenho daquelas.

As médias dos Grupos 1 e 2, nos três períodos estudados, podem ser observadas na Tabela 4 . No período inicial e médio, verifica-se superioridade do Grupo 1, formado pelas marcas comerciais, em relação ao Grupo 2, formado pelas linhagens da UFV. No período total, verifica-se superioridade do Grupo 2 , constituído apenas pela marca comercial $\mathrm{C}_{2}$, em relação ao Grupo 1, em algumas características, porém a diferença entre as médias foi reduzida, se comparada às diferenças dos períodos anteriores. Verifica-se que não existe diferença em relação à idade à maturidade sexual (IMS) entre os grupos. Com estes resultados, observou-se que as linhagens da UFV estão bem próximas de marcas comerciais existentes no mercado e enfatizam a necessidade da continuação do programa de melhoramento avícola desenvolvido na Universidade Federal de Viçosa .

Pela análise de variáveis canônicas, observou-se que as duas primeiras variáveis transformadas foram suficientes para explicar 99,69; 98,51; e 92,71\% da variação total nos dados originais, nos períodos inicial, médio e total, respectivamente (Tabela 5). Essas observações permitem estudar o comportamento das quatro linhagens por meio de duas variáveis canônicas com segurança nas informações, pois explicam a maior parte da variação total. Segundo CRUZ e REGAZZI (1997), quando as primeiras variáveis explicam mais de $80 \%$ da variação total, é viável o estudo da divergência genética por meio das distân-
Tabela 4 - Médias das características idade à maturidade sexual (IMS), número de ovos (NO), peso médio do ovo (PO) e peso das matrizes (PM), em cada grupo $^{1}$, nos três períodos ${ }^{2}$

Table 4 - Average of the traits age at sexual maturity (IMS), egg number (NO), average egg weight (PO) and body weight $(P M)$, in each group ${ }^{1}$, in the three periods ${ }^{2}$

\begin{tabular}{lcr}
\hline Característica & Grupo 1 & Grupo 2 \\
Trait & Group 1 & Group 2 \\
\hline \multicolumn{3}{c}{ Período inicial } \\
IMS & 189,75 & 187,05 \\
NO & 45,90 & 56,35 \\
PO & 64,73 & 60,78 \\
PM & 3468,75 & 3201,25 \\
\hline \multicolumn{3}{c}{ Período médio } \\
IMS & Medium period \\
NO & 187,05 \\
PO & 189,75 & 153,95 \\
PM & 150,35 & 65,00 \\
& 70,41 & 3698,10 \\
\hline \multicolumn{3}{c}{ Total period } \\
IMS & 3833,60 & 189,60 \\
NO & \multicolumn{2}{c}{680,00} \\
PO & 68,90 \\
PM & 66,79 \\
\hline
\end{tabular}

1 Obtidos pela análise de agrupamento.

2 Período inicial (25a a 32a $\underline{a}$ semana de idade), médio (48a a 56a semana de idade) e total (25a a $62^{a}$ a semana de idade).

1 Obtained by cluster analysis.

2 Initial ( $25^{\text {th }}$ to $32^{\text {nd }}$ week of age), medium ( $48^{\text {th }}$ to $56^{\text {th }}$ week of age) and total $\left(25^{\text {th }}\right.$ to $62^{\text {nd }}$ week of age) period.

cias entre linhagens em gráficos de dispersão, cujas coordenadas são escores relativos às primeiras variáveis canônicas.

Na Tabela 6, são apresentados, para os períodos inicial, médio e final, os autovetores associados às variáveis transformadas, relativos às quatro variáveis canônicas formadas. Observa-se, nos períodos inicial e médio, que as características peso médio do ovo e peso da matriz contribuíram positivamente para o valor dos escores da primeira variável canônica, o que indica que linhagens com maiores valores para estas características terão maiores escores para esta variável canônica. No período total, o peso médio do ovo e o peso da matriz, em menor escala, contribuíram positivamente para os valores dos escores da primeira variável canônica. A característica número de ovos contribuiu positivamente para a segunda variável canônica, indicando que a linhagem com 
maior número de ovos terá escore mais elevado que as demais linhagens para essa variável.

Os escores das variáveis canônicas para as quatro linhagens, nos três períodos estudados, encontram-se na Tabela 7. Estes mesmos escores foram plotados nas Figuras 1, 2 e 3, em um espaço bidimensional. A distância dos pontos é proporcional ao grau de dissimilaridade entre as linhagens e próxima aos resultados obtidos pelas técnicas de agrupamento, com base na distância generalizada de Mahalanobis $\left(\mathrm{D}^{2}\right)$.

As Figuras 1, 2 e 3 exibem a dispersão gráfica das quatro linhagens estudadas nos períodos inicial, médio e total, respectivamente, e, em conjunto com os resultados da Tabela 6 , indicam que:

- nos períodos inicial e médio, as duas marcas comerciais têm certa superioridade sobre as linhagens da UFV nos escores da $\mathrm{VC}_{1}$. No período total, a marca comercial $\mathrm{C}_{2}$ tem certa superioridade sobre as demais linhagens nos escores da $\mathrm{VC}_{1}$. Para os escores da $\mathrm{VC}_{2}$, que está relacionada com o número de ovos, a linhagem F1 foi superior às demais linhagens no período total; e

- as linhagens que formam o Grupo 1, nos perío- dos inicial e médio (linhas C1 e C2) caracterizaramse por terem as maiores médias para peso de ovo e peso de matrizes. No período total, o genótipo que forma o Grupo 2 (linha C2) caracterizou-se pelo maior peso médio de ovo e peso de matrizes.

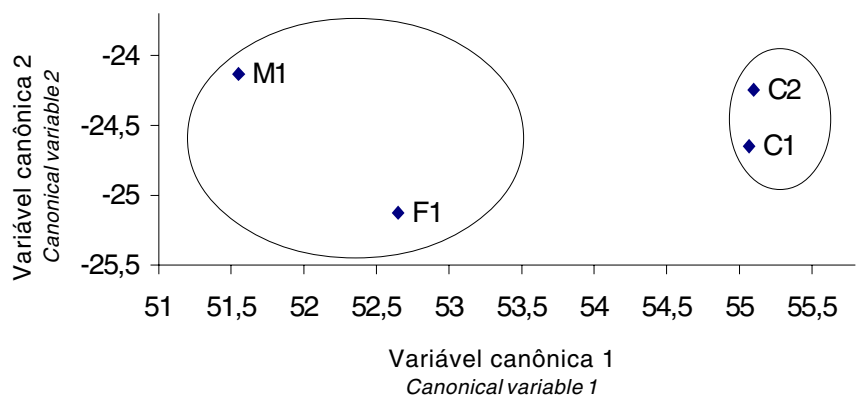

Figura 1 - Dispersão gráfica das quatro linhagens de matrizes de corte com relação às duas primeiras variáveis canônicas no período inicial e agrupamento estabelecido pelo método de Tocher com base na distância generalizada de Mahalanobis.

Figure 1 - Graphic dispersion of four broiler breeder lines of the first two canonical variables in the initial period and cluster obtained by Tocher method based on the generalized Mahalanobis distance.

Tabela 5 - Variáveis canônicas (VC), autovalores $\left(\lambda_{j}\right)$ e percentagens da variância $\left(\% \sigma^{2}\right)$ obtidas das quatro características nos três períodos ${ }^{\dagger}$

Table 5 - Canonical variables $(V C)$, eigenvalues $\left(\lambda_{j}\right)$ and percentages of variance $\left(\% \sigma^{2}\right)$ of four traits in the three periods ${ }^{1}$

\begin{tabular}{|c|c|c|c|}
\hline \multirow[b]{2}{*}{$\begin{array}{l}\text { Variável canônica } \\
\text { Canonical variable }\end{array}$} & \multicolumn{3}{|c|}{ Período inicial (Initial period) } \\
\hline & $\lambda^{2}$ & $\begin{array}{c}\% \sigma^{2}\left(\operatorname{para} \lambda_{i}\right) \\
\% \sigma^{2}\left(\text { for } \lambda_{i}\right)\end{array}$ & $\begin{array}{l}\% \sigma^{2} \text { (acumulada) } \\
\left.\% \sigma^{2} \text { (accumulated }\right)\end{array}$ \\
\hline $\mathrm{VC}_{1}$ & 3,1649 & 93,7339 & 93,7339 \\
\hline $\mathrm{VC}_{2}$ & 0,2012 & 5,9592 & 99,6931 \\
\hline $\mathrm{VC}_{3}$ & 0,0103 & 0,3037 & 99,9969 \\
\hline \multirow[t]{2}{*}{$\mathrm{VC}_{4}$} & 0,0001 & 0,0031 & 100 \\
\hline & \multicolumn{3}{|c|}{ Período médio (Medium period) } \\
\hline $\begin{array}{l}\text { Variável canônica } \\
\text { Canonical variable }\end{array}$ & $\lambda^{2}$ & $\begin{array}{c}\% \sigma^{2}\left(\operatorname{para} \lambda_{i}\right) \\
\% \sigma^{2}\left(\text { for } \lambda_{i}\right)\end{array}$ & $\begin{array}{l}\% \sigma^{2} \text { (acumulada) } \\
\left.\% \sigma^{2} \text { (accumulated }\right)\end{array}$ \\
\hline $\begin{array}{l}\mathrm{VC}_{1} \\
\mathrm{VC}_{2} \\
\mathrm{VC}_{3} \\
\mathrm{VC}_{4} \\
\end{array}$ & $\begin{array}{l}1,9904 \\
0,2871 \\
0,0344 \\
0,0001 \\
\end{array}$ & $\begin{array}{c}86,0928 \\
12,4183 \\
1,4880 \\
0,0009 \\
\end{array}$ & $\begin{array}{c}86,0927 \\
98,5110 \\
99,9990 \\
100 \\
\end{array}$ \\
\hline $\mathrm{VC}_{4}$ & \multicolumn{3}{|c|}{ Período total (Total period) } \\
\hline $\begin{array}{l}\text { Variável canônica } \\
\text { Canonical variable }\end{array}$ & $\lambda^{2}$ & $\begin{array}{c}\% \sigma^{2}\left(\operatorname{para} \lambda_{i}\right) \\
\% \sigma^{2}\left(\text { for } \lambda_{i}\right)\end{array}$ & $\begin{array}{l}\% \sigma^{2} \text { (acumulada) } \\
\left.\% \sigma^{2} \text { (accumulated }\right)\end{array}$ \\
\hline $\mathrm{VC}_{1}$ & 1,1397 & 74,9978 & 74,9978 \\
\hline $\mathrm{VC}_{2}$ & 0,2691 & 17,7099 & 92,7077 \\
\hline $\mathrm{VC}_{3}^{2}$ & 0,1108 & 7,2891 & 99,9968 \\
\hline $\mathrm{VC}_{4}$ & 0,0001 & 0,0032 & 100 \\
\hline
\end{tabular}


1080 Rev. bras. zootec.

Tabela 6 - Variáveis canônicas $\left(\mathrm{VC}_{\mathrm{i}}\right)$ autovetores associados aos autovalores, obtidos da análise das quatro características estudadas nos três períodos

Table 6 - Canonical variables $\left(V_{i}\right)$, eigenvectors associate to eigenvalues $\left(\lambda_{j}\right)$ obtained by the analysis of four traits in the three periods

\begin{tabular}{lcccc}
\hline & \multicolumn{4}{c}{ Período inicial (Initialperiod) } \\
\cline { 2 - 5 } $\mathrm{VC}_{\mathrm{i}}$ & ${ }^{1} \mathrm{Z}_{1}$ & $\mathrm{Z}_{2}$ & $\mathrm{Z}_{3}$ & $\mathrm{Z}_{4}$ \\
\hline $\mathrm{VC}_{1}$ & 0,261 & $-0,269$ & 0,695 & 0,614 \\
$\mathrm{VC}_{2}$ & $-0,353$ & $-0,092$ & $-0,560$ & 0,744 \\
$\mathrm{VC}_{3}$ & $-0,249$ & 0,908 & 0,271 & 0,198 \\
$\mathrm{VC}_{4}$ & 0,863 & 0,306 & $-0,361$ & 0,176 \\
\hline
\end{tabular}

Período médio (Medium period)

\begin{tabular}{ccccc}
\cline { 2 - 5 } $\mathrm{VC}_{\mathrm{i}}$ & $\mathrm{Z}_{1}$ & $\mathrm{Z}_{2}$ & $\mathrm{Z}_{3}$ & $\mathrm{Z}_{4}$ \\
\hline $\mathrm{VC}_{1}$ & 0,327 & 0,015 & 0,772 & 0,544 \\
$\mathrm{VC}_{2}$ & 0,120 & 0,897 & 0,197 & $-0,377$ \\
$\mathrm{VC}_{3}$ & 0,845 & $-0,292$ & $-0,038$ & $-0,446$ \\
\hline $\mathrm{VC}_{4}$ & 0,405 & 0,331 & $-0,603$ & 0,603
\end{tabular}

\begin{tabular}{lcccc} 
& \multicolumn{4}{c}{ Período total (Total period) } \\
\cline { 2 - 5 } $\mathrm{VC}_{\mathrm{i}}$ & $\mathrm{Z}_{1}$ & $\mathrm{Z}_{2}$ & $\mathrm{Z}_{3}$ & $\mathrm{Z}_{4}$ \\
\hline $\mathrm{VC}_{1}$ & 0,380 & $-0,113$ & 0,828 & 0,397 \\
$\mathrm{VC}_{2}$ & 0,378 & 0,891 & 0,276 & $-0,359$ \\
$\mathrm{VC}_{3}$ & 0,833 & $-0,182$ & $-0,170$ & $-0,495$ \\
$\mathrm{VC}_{4}$ & 0,401 & 0,400 & $-0,458$ & 0,685 \\
\hline
\end{tabular}

${ }^{1} Z_{1}, Z_{2}, Z_{3}$ e $Z_{4}$ são variáveis originadas da transformação por condensação pivotal, das variáveis originais: idade à maturidade sexual (IMS), número de ovos (NO), peso médio do ovo (PO) e peso das matrizes (PM).

$1 Z_{1}, Z_{2}, Z_{3} \in Z_{4}$ are traits obtained by pivotal condensation transformation of the actual traits: age at sexual maturity (IMS), egg number (NO), average egg weight $(P O)$ and body weight (PM).
Tabela 7 - Escores para as quatro linhagens nos três períodos, obtidos a partir das duas primeiras variáveis canônicas (VC)

Table 7 - Scores of the four lines in the three periods, obtained by means of the two first canonical variables (VC)

\begin{tabular}{|c|c|c|}
\hline \multirow[b]{2}{*}{$\begin{array}{l}\text { Linhagem } \\
\text { Line }\end{array}$} & \multicolumn{2}{|c|}{$\begin{array}{l}\text { Período inicial } \\
\text { Initial period }\end{array}$} \\
\hline & $1 \mathrm{a} V C$ & $2^{\mathrm{a}} \mathrm{VC}$ \\
\hline$\overline{\mathrm{C}_{1}}$ & 55,0681 & $-24,6502$ \\
\hline $\mathrm{C}_{2}$ & 55,0984 & $-24,2472$ \\
\hline $\mathrm{M}_{1}$ & 51,5520 & $-24,1337$ \\
\hline $\mathrm{F}_{1}$ & 52,6509 & $-25,1241$ \\
\hline & \multicolumn{2}{|c|}{$\begin{array}{l}\text { Período médio } \\
\text { Medium period }\end{array}$} \\
\hline $\begin{array}{l}\text { Linhagem } \\
\text { Line }\end{array}$ & $1^{\mathrm{a}} \mathrm{VC}$ & $2^{\mathrm{a}} \mathrm{VC}$ \\
\hline $\mathrm{C}_{1}$ & 55,8397 & $-0,9886$ \\
\hline $\mathrm{C}_{2}$ & 56,3726 & $-0,3470$ \\
\hline $\mathrm{M}_{1}$ & 53,2912 & $-0,8875$ \\
\hline \multirow[t]{2}{*}{$\mathrm{F}_{1}{ }^{\mathrm{I}}$} & 54,3146 & 0,1710 \\
\hline & \multicolumn{2}{|c|}{$\begin{array}{l}\text { Período total } \\
\text { Total period }\end{array}$} \\
\hline $\begin{array}{l}\text { Linhagem } \\
\text { Line }\end{array}$ & $1^{\mathrm{a}} \mathrm{VC}$ & $2^{\mathrm{a}} \mathrm{VC}$ \\
\hline$\overline{\mathrm{C}_{1}}$ & 60,7412 & $-3,0872$ \\
\hline $\mathrm{C}_{2}^{1}$ & 62,0158 & $-2,8099$ \\
\hline $\mathrm{M}_{1}$ & 59,4474 & $-3,0465$ \\
\hline $\mathrm{F}_{1}$ & 60,3341 & $-1,9729$ \\
\hline
\end{tabular}

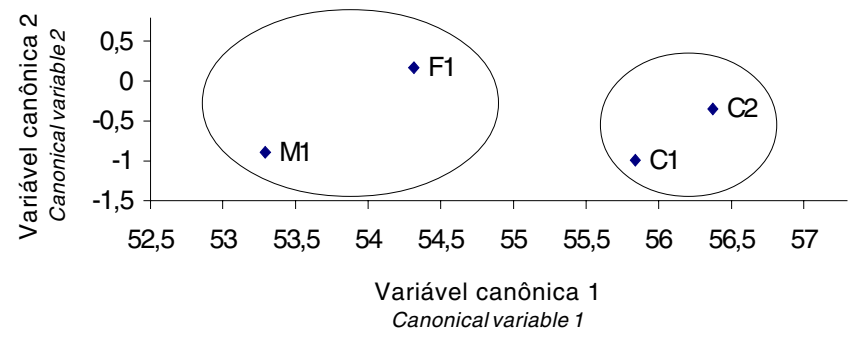

Figura 2 - Dispersão gráfica das quatro linhagens de matrizes de corte com relação às duas primeiras variáveis canônicas no período médio e agrupamento estabelecido pelo método de Tocher com base na distância generalizada de Mahalanobis.

Figure 2 - Graphic dispersion of four broiler breeder lines of the first two canonical variables in the medium period and cluster analysis by Tocher method based on the generalized Mahalanobis distance.

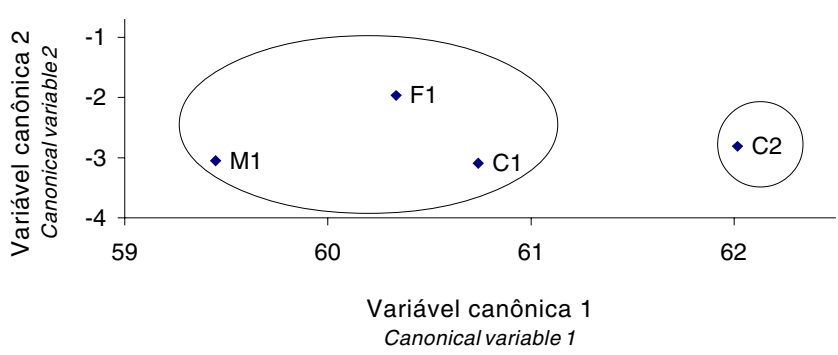

Figura 3 - Dispersão gráfica das quatro linhagens de matrizes de corte com relação às duas primeiras variáveis canônicas no período total e agrupamento estabelecido pelo método de Tocher com base na distância generalizada de Mahalanobis.

Figure 3 - Graphic dispersion of four broiler breeder lines of the first two canonical variables in the total period and clusters obtained by Tocher method based on the generalized Mahalanobis distance. 


\section{Conclusões}

As duas primeiras variáveis canônicas foram suficientes para explicar 99,69; 98,51; e 92,71\% da variação total existente nos períodos inicial, médio e total, respectivamente, o que possibilita representar o comportamento das linhagens utilizando apenas as duas primeiras variáveis canônicas.

Observou-se a existência de divergência genética entre as marcas comercias e as linhagens da UFV, sendo que o peso médio do ovo e o peso da matriz foram as características que mais contribuíram para esta divergência.

\section{Referências Bibliográficas}

ARAÚJO, C.F. Avaliação do desempenho de linhas de frango de corte em desenvolvimento na UFV e de seus cruzamentos em relação a duas marcas comerciais. Viçosa, MG: UFV, 1995. 108p. Dissertação (Mestrado em Genética e Melhoramento) - Universidade Federal de Viçosa, 1995.

CRUZ, C.D. Aplicação de algumas técnicas multivariadas no melhoramento de plantas. Piracicaba, SP: ESALQ, 1990. 188p. (Tese de Doutorado) - Escola Superior "Luiz de Queiroz", 1990.

CRUZ, C.D. 1991. Software aplicado à área de genética quantitativa e estatística experimental (Programa GENES). Viçosa, MG: UFV. 17p.
CRUZ, C.D., REGAZZI A.J. 1997. Modelos biométricos aplicados ao melhoramento genético. Viçosa, MG: UFV, 2.ed. 390p.

DEMETRIO, C.G.B. Análise multidimensional para dados de cana-de-açúcar. Piracicaba, SP: ESALQ, 1985. 144p. (Tese de Doutorado) - Escola Superior "Luiz de Queiroz", 1985.

HARRIS, G.C. 1975. A primer of multivariate statistics. New York: Acadenic Press. 322p.

PIASSI, M.A. Avaliação do desempenho de linhagens de postura mantidas na Universidade Federal de Viçosa, em competição com marcas comerciais. Viçosa, MG: UFV, 1994, 86p. Dissertação (Mestrado em Genética e Melhoramento) Universidade Federal de Viçosa, 1994.

RAO, C.R. 1952. Advanced statisticalmethods in biometric research. New York: Jonh Wiley \& Sons. 390p.

REGAZZI, A.J. 1997. Análise multivariada, Notas de Aula. Viçosa, MG: UFV, DPI.

SINGH, D. 1981. The relative importance of characters affecting genetic divergence. Ind. J. Genet., 41:237-45.

Recebido em: 18/12/1998

Aceito em: 09/02/2000 